\title{
Increasing Solar Panel Efficiency in a Sustainable Manner
}

\author{
Wim J.C. Melis ${ }^{\# 1}$, Sajib K. Mallick ${ }^{\# 2}$, Phillip Relf \#3 \\ \# School of Engineering, University of Greenwich \\ Central Avenue; Chatham Maritime; Kent ME4 4TB; United Kingdom \\ ${ }^{1}$ Wim.J.C.Melisegre.ac.uk \\ ${ }^{2}$ hellosajibeyahoo.com ${ }^{3}$ rp905egre.ac.uk
}

\begin{abstract}
Solar panel output is determined by a number of factors: obviously there is the type of panel that determines the conversion efficiency, but also the amount of light falling into the panel is of importance, among other conditions of operation. The output of a panel would e.g. drop when the amount of light falling onto it is reduced, or even when only a part of the panel is covered. Another reason for reduced output lies in the fact that the conversion efficiency drops by about $0.38 \%$ per ${ }^{\circ} \mathrm{C}$ increase in panel temperature. Considering that a panel would be able to produce most of its output on a sunny day, the reduction in efficiency due to heating up is of significant importance. To achieve an optimised output, it is therefore important for the panel to remain clean, but also keep it as cool as possible. Therefore, this paper looks at a method of running water on top of a solar panel in order to clean it and cool it down. To reduce the energy consumption of moving the water from the bottom of the panel back to the top, it exploits the kinetic energy of the water that runs down the panel to pump the water back to the top. Measurements indicate that this approach leads to an average increase in output of about $12 \%$.

Index Terms-Solar PV, Efficiency.
\end{abstract}

\section{INTRODUCTION}

Since the start of the energy crisis, there has been a growing interest in renewable energy sources. In many countries, due to a variety of government incentives, this has led to an increasing number of solar panels being mounted onto rooftops in urban environments. Currently, commercially available Photo-Voltaic (PV) panels have an efficiency between 10 and $30 \%$ [2]. Even though solar energy is free, in countries with less sun, it is of significant importance to ensure that the conversion into electricity is as high as possible. Hence, it is necessary to optimise all possible parameters where and when possible. To achieve optimal performance, there are a number of key aspects to take into account, e.g. the angle of the panel in relation to the ground level, to ensure that the solar rays fall into the panel in the most optimal way. Depending on the season, location around the planet etc, this angle should be changed for optimal efficiency. Hence a significant amount of research has been performed in creating solar tracking systems [1], [3]. Although these optimise the angle under which the rays fall into the panels, this does not ensure the light actually falls onto the panel, for which there could be a variety of reasons, like: dust, sand, leaves, etc..
The efficiency of existing panels is overall rather low and goes down even further when the panel heats up. Since the warming up would generally happen at those points in time when sun-light is most intense, the overall output decreases. Considering that the overall efficiency drops by about 0.38 $\%$ per ${ }^{\circ} \mathrm{C}$ [2], and considering that a panel can easily reach temperatures of 40 to $60{ }^{\circ} \mathrm{C}$ in full sun on a warm day, cooling could provide significant improvements in efficiency. Currently, most panels rely on passive cooling due to air flow along top and bottom of the panels. This passive cooling would however be the least effective at the time when most required, since the ambient temperature is already higher. On the other hand, active cooling systems have been proposed [4]. The problem with these active cooling systems is that they require energy to run, considering that most active cooling systems target large installations, one can more easily ignore the power consumption required to pump the water around. Applying these active cooling principles to a smaller system, often results in large overheads, which are generally larger than the actual gains achieved.

Consequently, this paper proposes a system that requires a minimal amount of energy to run water on top of the panels, in order to clean them and cool them down (Section 2). Current results are based on measuring the individual factors that influence the efficiency, combined with estimates about the required power consumption. The paper finishes with a conclusion.

\section{Proposed Design}

The easiest way to clean a panel as well as cool it down is by ensuring that there is a significant volume of water running over the panel. This could be achieved by sprinkling water onto the panel at the top and then collecting it again at the bottom. The collection of water at the bottom allows for it to be reused, but requires the water to be pumped up again to the top of the panel. Initial estimates quickly showed that when using a conventional water pump the pump's power consumption would be much higher than the efficiency gains obtained. If one is to pursue such a system, then it is important that the pumping mechanism consumes as little energy as possible. One way of achieving this is by making use of the kinetic 

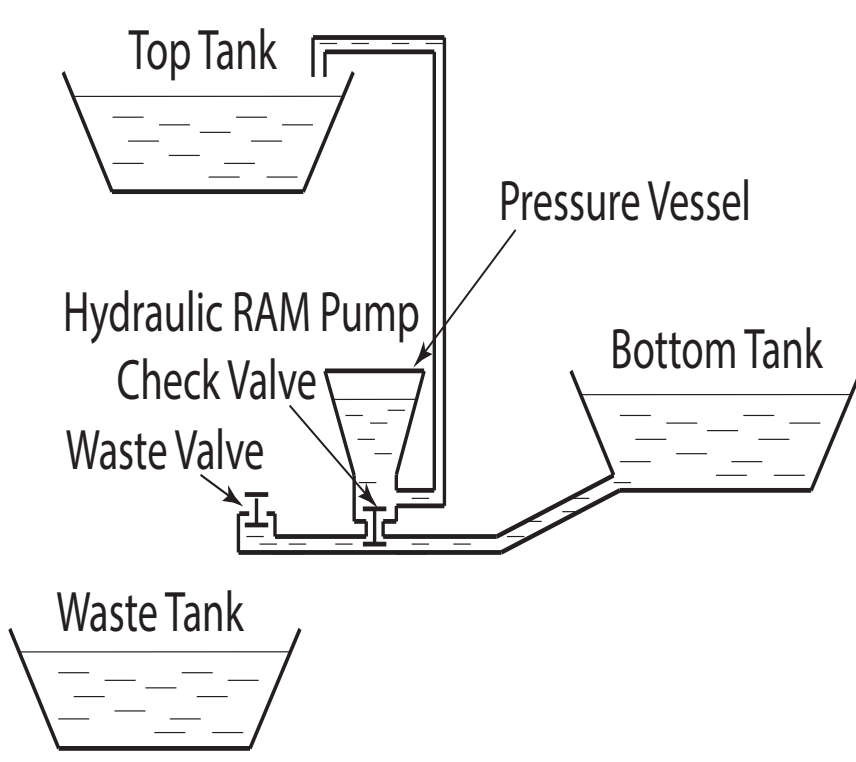

Fig. 1. Hydraulic RAM Pump

energy within the water, due to it just having fallen down the panel, and a Hydraulic RAM pump [5] exploits this principle.

Figure 1 shows the schematic of a Hydraulic RAM Pump. Typically, a Hydraulic RAM pump has two different valves that close/open depending on the pressure they experience. When the water streams in from the bottom tank, the pressure on the waste valve will increase until the valve closes. From then onwards the water will no longer escape through the waste valve, but go into the pressure vessel. Water will continue to run into this vessel until the downward pressure is higher than the one from the water flowing into the vessel, which would result in the closing of the check valve. Consequently, the water from the pressure valve escapes upwards to the top tank. After which the complete cycle starts again. A well designed Hydraulic RAM pump can pump water up to about 10 times higher than the drop between the bottom water tank and the pipe leading to the vessel and waste valve. Although this pumping mechanism ensures free pumping, the disadvantage is that there is only about $20 \%$ of the water that will reach the higher tank. Hence about $80 \%$ of the water coming from the bottom tank ends up in the waste tank.

Due to the high amount of wasted water, a water tank to collect this waste water is used. In an attempt to recover this wasted water, an extra pump was introduced. Rather than using a normal water pump, a Tesla pump [6] was selected, because it is one of the most efficient water pumping mechanisms. A Tesla pump in essence has a number of disks which are mounted close to one another and close to the central axis there would be a number of holes in these disks. The pump could be used in two ways, either when receiving water to drive a generator, or when driven by an electric motor to drive water up. In this specific project, a double chamber approach is used to exploit the remaining kinetic energy from the water flowing out of the Hydraulic RAM pump, while the second chamber is used to drive the water upwards. An electrical motor would be added to the system to cover up for the losses in the system. The system overview shown in Figure 2 indicates that the waste water tank is only slightly lower than the bottom tank. Considering that the Hydraulic RAM pump operates for free, and takes care of the higher elevation, it was considered more efficient to use the Hydraulic RAM pump to deal with the higher elevation and keep it fed with water by pumping the waste water back into the bottom tank for which the Tesla pump is used. From the Tesla pump output, there is also a pipe running to the top tank, which has a valve installed so that one can switch the operation of the output of the Tesla pump as required.

It is expected that in climates with rainy and sunny weather, the rain water can be used to fill up the water supply of the system, but if necessary then the system can be topped up by supplying water into the waste tank at the bottom and pumping it up with the Tesla pump. The controller designed for this system takes care of regular flooding of the panel for which it controls a number of different parts of the system. There is one valve used to control the sprinkling of the solar panel and this valve is opened with a frequency corresponding to the temperatures of the system. However, if the humidity is high, which would imply there is rain, then the system would not sprinkle the panels at all. Secondly, there is a valve located between the bottom tank and the Hydraulic RAM pump, which is meant to prevent the RAM pump from running dry, for which the micro-controller checks the water level in the bottom tank. The water level in the waste water tank allows for the controller to switch on the Tesla pump as required.

\section{RESULTS \& DisCUSSION}

Initial measurements of the system are based on looking at each of the individual factors that influence the overall system. All tests were performed using two identical panels installed at an angle of $50^{\circ} \mathrm{C}$, a battery was connected to the panels as a load, while a voltage regular was used to provide the correct power needed to charge the battery. The tests were performed three times for a specific period and these results were then used to determine average values. A first measurement looked at the change in efficiency based on the panels being covered by dirt. The results in Table I show that there is a clear difference between normal usage and the panels being covered by small dust particles (i.e. sand) or large dirt (i.e. moss and leaves). Small dust particles indicate an efficiency drop of about $17 \%$, whereas larger particles lead to an efficiency loss of nearly $30 \%$. So when panels are covered with dirt this could result in a reduction of output power of up to one third. To confirm these measurements, a similar test was performed on second set of panels, with different specifications, which showed similar results.

The second effect that was measured was the output in relation to the temperature of the panel. Unfortunately the set of results is limited due to the weather conditions presented during the time of test. Table II shows the results in which one 


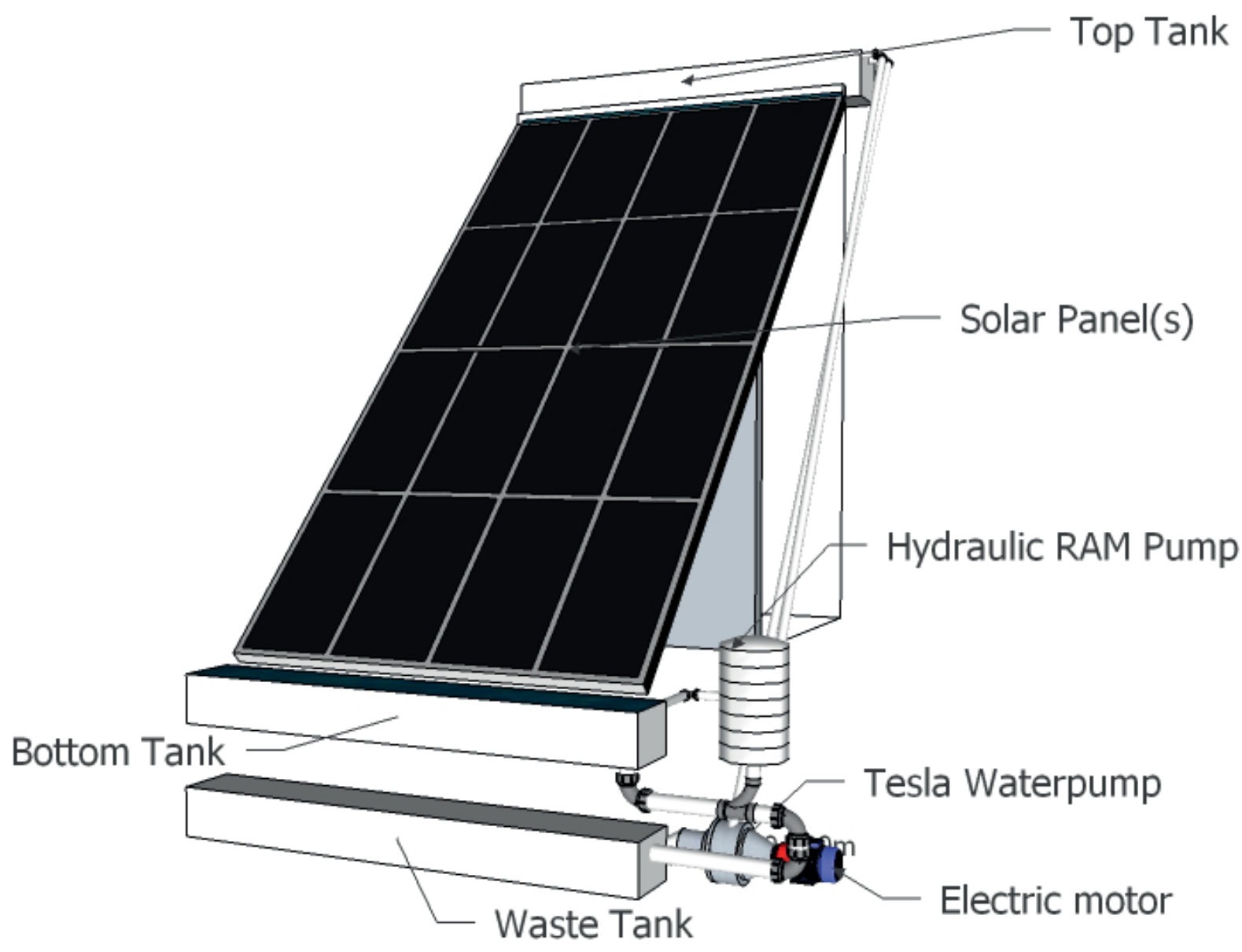

Fig. 2. System Overview

TABLE I

EFFICIENCy Changes For WHEN DiRT Covers the Solar PANEL

\begin{tabular}{c|ccc} 
& $\begin{array}{c}\text { Power Output } \\
\text { Clean (W) }\end{array}$ & $\begin{array}{c}\text { Power Output } \\
\text { Dirty (W) }\end{array}$ & $\begin{array}{c}\text { Efficiency } \\
\text { Decrease \% }\end{array}$ \\
\hline Small Particles & 13.40 & 11.02 & 17.8 \\
Large Particles & 19.01 & 13.40 & 29.6
\end{tabular}

TABLE II

POWER OUTPUT IN RELATION TO PANEL TEMPERATURE

\begin{tabular}{c|cc} 
& Temperature $\left({ }^{\circ} \mathrm{F}\right)$ & Power Output $(\mathrm{W})$ \\
\hline Measurement 1 & 155 & 3483 \\
Measurement 2 & 89 & 3977
\end{tabular}

can clearly notice a significantly higher output when the panel temperature is lower, leading to an overall efficiency increase of about $14 \%$.

On the other hand, there is a further factor that could influence the overall efficiency. Namely, when there is water on top of the panel, then this water would introduce an extra material/layer and since it has a different breaking index it could influence the light falling into the panel. The influence of this effect had to be measured as it was difficult to make initial estimates on the effect of this on the overall panel output.
TABLE III

POWER OUTPUT IN RELATION TO BEING COVERED WITH WATER

\begin{tabular}{c|cc}
$\begin{array}{c}\text { Power Output } \\
\text { Dry Panel (W) }\end{array}$ & $\begin{array}{c}\text { Power Output } \\
\text { Wet Panel (W) }\end{array}$ & $\begin{array}{c}\text { Efficiency } \\
\text { Increase \% }\end{array}$ \\
\hline 10.80 & 11.67 & 8
\end{tabular}

Considering the results obtained and presented in [4], it seems that a layer of water results in a slightly higher efficiency for the panel. A similar measurement was repeated on the same test panel used for the first measurements, with the results presented in Table III. This table clearly indicates that if the panel is covered with water, the efficiency increases. It is however essential to mention that the covering needs to be a full film of water over the panel rather than a few drops spread across the panel, the latter namely has no effect on the output. When a thin layer of water is present on the panel, then the efficiency increases about $8 \%$. The reason for this positive effect lies most likely in the fact that when the sun rays fall into the water, due to the different braking index for the water layer, the light gets scattered around, which results in a certain kind of amplification of the light falling into the panel, consequently leading to the higher output. 
As a final measure, estimates were made about the overall power consumption to run the system, this comprises the small controller as well as the Tesla pump required to pump the water from the waste water tank back to the bottom tank. According to initial estimates, these power requirements would be about $70 \mathrm{~W}$ for a normal size solar panel installed on a roof with an average roof pitch. Overall, considering each of the individual components it is expected that improvements of about $12 \%$ in electrical production efficiency will be obtained.

\section{CONCLUSION}

In order to improve the output of solar panels, this paper presents a method to clean the panels as well as cool them down. Both of these tasks are achieved by running water over the top of the panel, for which an energy efficient method is proposed. The method exploits the kinetic energy within the water that flows down the panel. A Hydraulic RAM pump is used to pump the water from the bottom tank up to the top tank. Due to the large amount of waste water when using a Hydraulic RAM pump a Tesla pump is used to pump the water from the waste tank back into the bottom tank.

A control system was designed to take care of flowing water over the panel in dry weather. The control system also measures the panel temperature and increases the frequency of running water over the panels when the temperature of the panels has increased, in order to cool them back down. Furthermore, the system takes care of the water levels in the different tanks while allowing easy topping up.

Initial measurements indicate that the cleaning and cooling down of panels leads to significant improvements in panel efficiency. On top of that, the water film covering the panel during cleaning leads to a positive effect on the overall panel efficiency. On the other hand, the power requirements for the system are much smaller than the gains obtained, leading to an overall efficiency improvement of about $12 \%$.

Due to the promising results obtained from the initial tests, this project will be further developed towards a prototype. From there on, the research will focus on the possible extraction of heat from the water being circulated over the solar panel.

\section{REFERENCES}

[1] Dousoky, G.M., El-Sayed, A.-H.M., Shoyama, M. "Maximizing EnergyEfficiency in Single-Axis Solar Trackers for Photovoltaic Panels" IEEE 8th International Conference on Power Electronics and ECCE Asia, May 30 - June 3 2011, Pages 1458-1463.

[2] MacKay, D. J.C., "Sustainable Energy - Without the Hot Air", 2008, Pages 384, Also Available Online: www.withouthotair.com.

[3] Mokhtari, B., Ameur, A., Mokrani, L. Benkhoris, M.F., "DTC applied to Optimize Solar Panel Efficiency", IEEE 35th Annual Conference of Industrial Electronics, 3-5 Nov 2009, Pages 1122-1127.

[4] Prudhvi, P., Chaitanya, S. P., "Efficiency Improvement of Solar PV panels using Active Cooling", 11th International Conference on Environment and Electrical Engineering EEEIC, 18-25 May 2012, Pages 1093-1097.

[5] Wikipedia, "Hydraulic RAM Pump", Available Online: http://en. wikipedia.org/wiki/Hydraulic_ram, Accessed on: 27/09/2012.

[6] Wikipedia, "Tesla Turbine", Available Online: http://en.wikipedia.org/ wiki/Tesla_turbine, Accessed on: 27/09/2012. 